
structure in prepubertal adolescents stratified according to sports practice. height velocity. ness (IMT) in hypertensive adults ${ }^{6}$ and also in healthy adolescents. ${ }^{7,8}$ and overweight, blood pressure, and dyslipidemia in adults. ${ }^{9}$ the active ones, independent of body fatness and biological maturation.

The data presented in this study were collected from the baseline measures of a cohort study, which is being carried out in the city of Presidente Prudente (200 000 inhabitants; western Sao Paulo State, Brazil). This study started in the
APHV
CIMT
Age at peak of height velocity
fIMT
HDL-c
hsCRP
IMT
max Bflow femora

\section{The Mediating Role of Physical Inactivity on the Relationship between Inflammation and Artery Thickness in Prepubertal Adolescents}

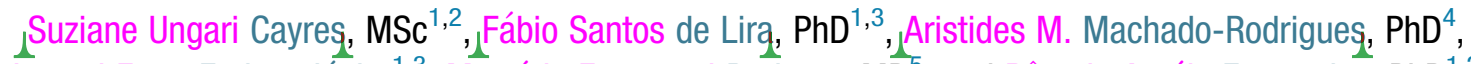

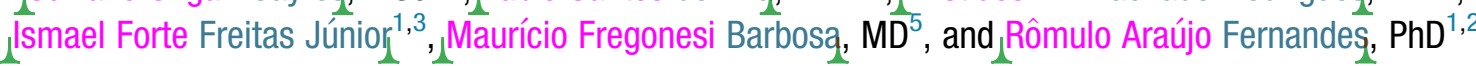

Objective To analyze the relationship between inflammatory markers and the lipid profile, blood flow, and artery

Study design The sample was composed of 120 adolescents (57 boys and 63 girls) with a mean age of $11.7 \pm 0.7$ years (ranging from 11 to 13 years). Intima-media thickness (IMT) and blood flow were measured with ultrasonography. The lipid profile and high-sensitivity C-reactive protein were measured after the subjects had fasted for 12 hours overnight. Trunk fatness was measured by dual-energy $\mathrm{x}$-ray absorptiometry. Organized sports participation was analyzed as a categorical variable. Biological maturation was determined via the age at peak

Results In the adjusted model, high-sensitivity C-reactive protein was significantly related to high-density lipoprotein-cholesterol $(\beta=-5.797$ [ -11.500 to -0.093$])$, femoral IMT ( $\beta=0.062[0.008-0.116])$, and the sum of femoral and carotid IMT ( $\beta=1.107$ [0.223-1.919]), but only in the group without sports participation. Slopes of the crude linear regression were greater in the group without sports participation for femoral IMT $(\mathrm{t}=2.621 ; P=.009)$ and the sum of femoral and carotid IMT $(\mathrm{t}=2.876 ; P=.004)$ when compared with the group with sports participation.

Conclusion Independent of body fatness and biological maturation, inflammatory status was related to artery IMT and dyslipidemia in prepubertal adolescents, modulated by sport participation. (J Pediatr 2015; $\mathbf{\square} \mathbf{\square}-\mathbf{\square})$.

igh-sensitivity C-reactive protein (hsCRP) is an acute-phase protein produced by the liver in response to interleukin-6, which is directly related to vascular inflammation. ${ }^{1,2}$ During the atherosclerotic process, hsCRP is associated with greater permeability of the intima layer through stimuli of intercellular/vascular cell adhesion molecules. hsCRP also acts in processes related to oxidation of lipoproteins in the vascular wall. ${ }^{2,3}$ Strategies to counteract inflammation status commonly include both pharmacologic and nonpharmacologic strategies. In the latter, lifestyle changes frequently are used, especially improved diet, giving up smoking, and practicing physical exercise. ${ }^{4}$ Indeed, physical exercise at moderate intensity plays an anti-inflammatory role. ${ }^{4,5}$ Its prolonged practice has been linked to the control the progression of intima-media thick-

Recently, studies have reported that behavioral variables can modulate the relationship between the progression of artery IMT and its risk factors. ${ }^{9,10}$ For instance, smoking exacerbates the relationship between age and the metabolic syndrome components and age and carotid IMT (cIMT) in young adults. ${ }^{10}$ In contrast, the same harmful effect related to age has been observed relating to physical inactivity. ${ }^{9}$ However, physical inactivity seems to exacerbate the relationship between cIMT

The objective of the present study was to analyze the relationship between hsCRP and the lipid profile, blood flow, and artery IMT in prepubertal adolescents who were stratified according to their engagement in sports practice. It was hypothesized that inflammation would be positively and strongly related to cardiovascular/metabolic outcomes in inactive youth compared with

\section{Methods}

From the ${ }^{1}$ Post-Graduate Program in Movement 1 Sciences, São-Paulo State University-UNESP, Rio Claro, Brazil; 'Laboratory of Investigation in Exer

Department of Physical Education, and
${ }^{3}$ Immunometabolism Research Group, Department of

Physical Education, São Paulo State University-UNESP Presidente Prudente, SP, Brazil; ${ }^{4}$ Faculty of Sport

Sciences and Physical Education, University of Coimbra, Coimbra, Portugal; and ${ }^{5}$ Program of Post-Graduate in

Radiology, Federal University of-São Paulo (UNIFESP),

São Paulo, Brazil

Funded by the State of Sao Paulo Research Support Foundation (FAPESP [Process: 2013/06052-2]) and CNPq (Process: 476295/2013-0). The authors declare no CNPq (Process: 476295/2013-0). The authors declare no
conflicts of interest. All rights reserved.

http://dx.doi.org/10.1016/j.jpeds.2014.12.057
0022-3476/\$ - see front matter. Copyright ๑ 2015 Elsevier Inc 
second half of 2013 and has follow-up measures scheduled for the second half of 2014 (August/September). Before data collection, the minimum sample size was calculated ${ }^{11}$ based on previous data about the expected relationship between cIMT and hsCRP $(\mathrm{r}=0.28$, power of $80 \%$, alpha of $5 \%$, and predicted loss of $20 \%),{ }^{7}$ which identified that a minimum of 118 participants were needed.

Seven large public and primary schools in the metropolitan region of the city were invited to participate in the study and participants were recruited from the 3 schools that agreed to participate; all schoolchildren between 11 and 14 years of age were invited to participate in the cohort (overall students $n=495$ adolescents), and the following inclusion criteria were adopted: (1) age between 11 and 14 years; (2) regularly enrolled in the school unit; (3) absence of any known diseases; (4) no regular medicine use; and (5) signature of parents/legal guardians.

Sex and chronological age were established during faceto-face interview, and the final sample was composed of 120 adolescents of both sexes ( 57 boys and 63 girls) with a mean age of $11.7 \pm 0.7$ years (ranging from 11 to 13 years). The study was previously approved by the Human Research Ethics Committee (process: 322.650/2013) of the São-Paulo State University (UNESP), Brazil.

Blood samples were collected in the morning after the subjects had fasted for 12 hours overnight by a nurse in a private laboratory that meets all the quality control standards adopted by the Brazilian Health Ministry. The following biochemical variables were measured: total cholesterol, high-density lipoprotein-cholesterol (HDL-c), low-density lipoprotein cholesterol and triacylglycerol, using an enzymatic colorimetric kit processed in an Autohumalyzer (Dimension RxL Max; Siemens Dade-Behring, Deerfield, Illinois). hsCRP was determined through the turbidimetric method (LabMax 240; Chema Diagnostica, Monsano, Italy) using an enzyme kit (Millipore, St. Charles, Missouri [intra- and interassay coefficients ranging between 4.6 and $6.0 \mathrm{kit} \%$, respectively]).

A continuous score was computed using the 4 lipid variables. Each lipid variable was standardized ([value mean]/SD; HDL-c Z-scores were multiplied by -1 ). The $z$-scores of the individual lipid variables were then summed to create a cluster of lipid variables which are identified in the present study as "dyslipidemia."

The IMT (cIMT and femoral IMT [fIMT] arteries) and maximum blood flow (maximum carotid artery blood flow and maximum femoral artery blood flow [max Bflow femoral $_{\text {f }}$ ) were assessed with a Doppler ultrasound examination (HD11 XE; Philips, Barueri, Brazil), equipped with a high-resolution, multifrequency linear transducer (set to $12 \mathrm{MHz}$ ). Reproducibility measures were provided by cIMT (ICC: $\left.0.57 ; P_{\perp}=.029\right)$ and fIMT (ICC: $\left.0.91 ; P_{\mathbf{\Lambda}}=.001\right)$ in $13.3 \%$ of the sample ( $\mathrm{n}=16$ adolescents).

Measurements of the blood flow were carried out (simultaneously with IMT measurements) in centimeters per second $(\mathrm{cm} / \mathrm{s})$, obtaining maximum values of systolic peaks using an automatic method. ${ }^{12}$ The common carotid artery and femoral artery (right side) were assessed to estimate
IMT (distance between 2 echogenic lines that show the lumen/intima interface and media/adventitia of the arterial wall). ${ }^{12,13}$ When testing the common carotid artery, the neck was slightly hyperextended and inclined at an angle of 45 degrees. To assess the femoral artery, the adolescent's leg was stretched out on the bed and the measurement was performed near the inguinal line. Each value of arterial IMT also was standardized ([value - mean]/SD) and thus a continuous score was created through the sum of both variables $\left(\mathrm{cIMT}+\mathrm{fIMT}_{\mathrm{z} \text {-score }}\right)$.

Body fatness was assessed using a dual-energy x-ray absorptiometry scanner (Lunar DPX-NT; General Electric Healthcare, Little Chalfont, Buckinghamshire, United Kingdom) with GE Medical System Lunar software (version 4.7). The scanner quality was tested by a trained researcher before each day of measurement, following the manufacturer's recommendations. Both whole body and trunk fatness were assessed. The participants wore light clothing, without shoes, and remained in the supine position on the machine (approximately 15 minutes).

Organized sports participation (competitive sports activity developed under instruction of a teacher/coach and performed outside school) was evaluated during a face-to-face interview. Sports practice was determined by asking participants the following 2 questions: (1) "Are you engaged in any sports activity outside high school?"; and (2) if yes, "How many days per week?" In this study, the group of sport practice was composed of adolescents engaged in any sport practice outside school for at least 1 day per week (in this sample, ranging from 1-5 days/week), and the other group was composed of adolescents who reported no sport practice. After the face-to-face interview, the adolescent received a pedometer (Yamax Digiwalker [model SW200]) to be used for 7 consecutive days to measure free-living physical activity. The participants wore the pedometer over the hip and were instructed to remove the monitor when involved in swimming activities, while showering, or sleeping. ${ }^{14}$ In this sample, the adolescents who engaged in sports activity were more active than those who did not, identifying that the questions on sports practice identified the more active adolescents (the number of days devoted to sports practice was related to mean step count, $\mathrm{r}=0.21$ [95\% CI 0.02-0.37], and there was an association between sports practice and step count found in the guidelines ${ }^{14}$ : OR $2.41[95 \% \mathrm{CI}$ 1.12-5.16]).

Body weight was measured using an electronic scale (Filizzola PL 150; Filizzola Ltda, São Paole, Brazil), and height using a wall-mounted stadiometer (Sanny; American Medical of the Brazil Ltda). The leg length and sitting-height also were assessed via standardized techniques. These measurements were used to calculate the maturity offset, which denotes the time (years) from/to peak of height velocity, an important maturational event. ${ }^{15}$ Peak of height velocity is an indicator of somatic maturity and reflects the age of maximum growth rate in stature during adolescence (age at peak of height velocity [APHV]). In the present crosssectional study, the number of years until APHV was 
Table I. Characteristics of the adolescents stratified according to tertiles of hsCRP $(n=120)$

\begin{tabular}{|c|c|c|c|c|}
\hline \multirow[b]{2}{*}{ Variables } & \multicolumn{3}{|c|}{ hsCRP, mg/L } & \multirow[b]{2}{*}{ One-way ANOVA, $P$ value } \\
\hline & Tertile $1(n=39)$, mean (SD) & Tertile $2(n=41)$, mean (SD) & Tertile $3(n=40)$, mean $(S D)$ & \\
\hline \multirow{2}{*}{\multicolumn{5}{|c|}{$\begin{array}{l}\text { II/F } \\
\text { General }\end{array}$}} \\
\hline & & & & \\
\hline Age, y & $11.7(0.7)$ & $11.8(0.8)$ & $11.6(0.6)$ & .487 \\
\hline Body mass, $\mathrm{kg}$ & 43.9 (7.4) & $52.4(12.1)^{*}$ & $56.7(14.8)^{\star}$ & .001 \\
\hline Height, $m$ & $1.53(0.06)$ & $1.57(0.06)^{*}$ & $1.53(0.06)^{\dagger}$ & .019 \\
\hline TF, \% & $25.1(8.1)$ & $32.9(11.1)^{*}$ & $38.3(11.2)^{*, \dagger}$ & .001 \\
\hline $\mathrm{BMI}, \mathrm{kg} / \mathrm{m}^{2}$ & $18.4(2.3)$ & $20.8(3.7)^{\star}$ & $23.6(4.9)^{*, \dagger}$ & .001 \\
\hline Maturity offset, y & $-2.3(0.6)$ & $-2.2(0.7)$ & $-2.5(0.9)$ & .080 \\
\hline \multicolumn{5}{|l|}{ Lipid profile, mg/dL } \\
\hline HDL-C & $54.1(12.4)$ & $50.2(9.2)$ & $46.1(10.2)^{\star}$ & .006 \\
\hline LDL-C & $91.1(19.7)$ & $97.6(21.2)$ & $96.8(20.9)$ & .313 \\
\hline $\mathrm{TG}$ & $71.7(25.9)$ & $88.5(43.6)$ & $86.8(41.2)$ & .099 \\
\hline TC & $159.5(24.3)$ & $167.1(26.4)$ & $\begin{array}{l}160.2(24.1) \\
-\end{array}$ & .326 \\
\hline Dyslipidemiaz-score & $-1.39(2.1)$ & $0.35(2.9)^{*}$ & $1.03(2.8)^{\star}$ & .001 \\
\hline \multicolumn{5}{|l|}{ Thickness, mm } \\
\hline CIMT & $0.45(0.02)$ & $0.46(0.05)$ & $0.45(0.03)$ & .164 \\
\hline fIMT & $0.37(0.06)$ & $0.38(0.06)$ & $0.40(0.09)$ & .218 \\
\hline cIMT + fIMT & $-0.21(1.1)$ & $0.16(1.7)$ & $0.07(1.6)$ & .514 \\
\hline \multicolumn{5}{|l|}{ Blood flow, $\mathrm{cm} / \mathrm{s}$} \\
\hline Max Bflow & $133.1(27.9)$ & $133.3(30.9)$ & $140.5(25.7)$ & .411 \\
\hline Max Bflow femoral & 136.1 (27.3) & $146.1(23.5)$ & $155.8(32.1)^{\star}$ & .009 \\
\hline \multicolumn{5}{|l|}{ Physical activity } \\
\hline Steps, d & $8805(3550)$ & $9525(4180)$ & $10076(4180)$ & .348 \\
\hline
\end{tabular}

$B M I$, body mass index; $F$, female; $L D L-C$, low-density lipoprotein cholesterol; $M$, male; Max Bflow carotid, maximum blood flow in carotid artery; $T C$, total cholesterol; $T F$, trunk fatness; $T G$, triacylglycerol.

${ }^{\star} P<.05$ compared with Tertile 1.

$\dagger P<.05$ compared with Tertile 2.

predicted for each individual using a sex-specific multiple regression equation that included height, sitting height, leg length, chronological age, and their interactions. ${ }^{15}$ The prediction of years until APHV results in a continuous measure of biological age and biological age categories were constructed using 1-year intervals.

\section{Statistical Analyses}

Descriptive statistics were composed of mean and SD. One-way ANOVA was used to compare numerical variables according to tertiles of hsCRP (Tukey post hoc test was used when necessary). Bivariate and partial correlation (age, sex, trunk fatness, and age at peak height velocity as covariates) were applied to analyze the relationship between hsCRP and the dependent variables. Finally, signifi- cant relationships were inserted into a multivariate model (crude and adjusted [simultaneously by age, sex, trunk ${ }^{11}$ fatness, and somatic maturation $]_{1}$ and the crude models were compared using the Student $t$ test. Statistical significance was set at $P_{\Lambda}<, 05$ and all statistical analyzes were performed using the software BioEstat (version 5.0, Tefé, Amazonas, Brazil).

\section{Results}

The characteristics of the adolescents stratified according to hsCRP tertiles are presented in Table I. Maturity offset ranged from -6.07 years to -0.86 years to APHV and sports practice was reported by $50 \%$ (95\% CI $41.1 \%$ $58.9 \%)$ of the sample. Among the adolescents who

Table II. Bivariate and partial correlations between inflammation and lipid profile in adolescents stratified according to sport practice $(\mathrm{n}=120)$

\begin{tabular}{|c|c|c|c|c|c|}
\hline Independent variable & HDL-C, $r(95 \%$ Cl) & LDL-C, $r(95 \%$ Cl) & TG, $r(95 \% \mathrm{Cl})$ & TC, $r(95 \%$ Cl $)$ & Dyslipidemia $_{\text {z-score, }} r(95 \% \mathrm{Cl})$ \\
\hline 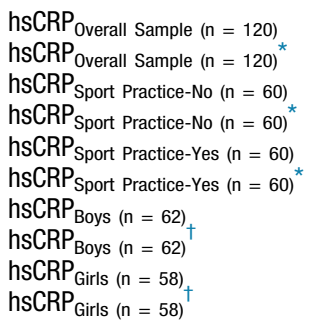 & $\begin{array}{l}-\mathbf{0 . 3 2}(-0.47 \text { to }-0.15) \\
-\mathbf{0 . 2 1}(-0.37 \text { to }-0.03) \\
-\mathbf{0 . 3 4}(-0.54 \text { to }-\mathbf{0 . 0 9}) \\
-\mathbf{0 . 2 6}(-0.48 \text { to }-\mathbf{0 . 0 2}) \\
-\mathbf{0 . 3 1}(-0.52 \text { to }-0.05) \\
-0.15(-0.39 \text { to } 0.10) \\
-\mathbf{0 . 3 3}(-0.53 \text { to }-0.08) \\
-0.14(-0.38 \text { to } 0.10) \\
-\mathbf{0 . 3 2}(-\mathbf{0 . 5 3} \text { to }-\mathbf{0 . 0 7}) \\
-0.21(-0.45 \text { to } 0.04)\end{array}$ & $\begin{array}{r}0.07(-0.11 \text { to } 0.24) \\
-0.05(-0.22 \text { to } 0.13) \\
0.15(-0.10 \text { to } 0.39) \\
0.04(-0.21 \text { to } 0.29) \\
0.03(-0.22 \text { to } 0.28) \\
-0.09(-0.33 \text { to } 0.16) \\
0.08(-0.17 \text { to } 0.32) \\
-0.11(-0.35 \text { to } 0.14) \\
0.05(-0.20 \text { to } 0.31) \\
-0.01(-0.26 \text { to } 0.25)\end{array}$ & $\begin{array}{r}0.10(-0.08 \text { to } 0.27) \\
-0.08(-0.25 \text { to } 0.09) \\
0.18(-0.07 \text { to } 0.41) \\
-0.05(-0.30 \text { to } 0.20) \\
0.14(-0.11 \text { to } 0.38) \\
-0.01(-0.25 \text { to } 0.25) \\
0.03(-0.21 \text { to } 0.28) \\
-0.18 \text { (-0.41 to } 0.06) \\
0.19 \text { (-0.06 to } 0.43) \\
-0.02 \text { (-0.28 to } 0.23)\end{array}$ & $\begin{array}{r}-0.06(-0.23 \text { to } 0.12) \\
-0.15(-0.32 \text { to } 0.02) \\
0.04(-0.21 \text { to } 0.29) \\
-0.09(-0.16 \text { to } 0.33) \\
-0.11(-0.35 \text { to } 0.15) \\
-0.17(-0.40 \text { to } 0.08) \\
-0.06(-0.30 \text { to } 0.19) \\
-0.21(-0.43 \text { to } 0.04) \\
-0.05(-0.31 \text { to } 0.20) \\
-0.11(-0.36 \text { to } 0.14)\end{array}$ & $\begin{array}{l}\mathbf{0 . 2 9}(\mathbf{0 . 1 2 - 0 . 4 5 )} \\
0.03(-0.14 \text { to } 0.21) \\
\mathbf{0 . 3 9}(\mathbf{0 . 1 5 - 0 . 5 8 )} \\
0.13(-0.12 \text { to } 0.37) \\
\mathbf{0 . 2 6}(\mathbf{0 . 0 1 - 0 . 4 8 )} \\
0.02(-0.23 \text { to } 0.27) \\
\mathbf{0 . 2 8}(\mathbf{0 . 0 3 - 0 . 4 9 )} \\
-0.07(-0.31 \text { to } 0.18) \\
\mathbf{0 . 3 1}(\mathbf{0 . 0 6 - 0 . 5 3 )} \\
0.08(-0.18 \text { to } 0.33)\end{array}$ \\
\hline
\end{tabular}

${ }^{*}$ Controlled by age, sex, TF and somatic maturation.

tControlled by age, TF, and somatic maturation,
300

301

302

303

304

305

306

307

308

309

310

311

T1] 312

313

314

315

316

317

318

319

320

321

322

323

324

325

326

327

328 
Table III. Bivariate and partial correlation between inflammation, IMT, and blood flow among adolescents stratified according to sport practice $(n=120)$

\begin{tabular}{|c|c|c|c|c|c|}
\hline Independent variable & cIMT, $r(95 \%$ CI $)$ & Max Bflow carotid, $r(95 \% \mathrm{Cl})$ & flMT, $r(95 \% \mathrm{Cl})$ & $\begin{array}{c}\text { Max } \text { Bflow }_{\text {femoral }} \\
r(95 \% \mathrm{CI})\end{array}$ & $\begin{array}{c}\text { clMT + flMT } \\
r(95 \% \text { Cl })\end{array}$ \\
\hline hsCRP $_{\text {Overall Sample }(n=120)}$ & $-0.06(-0.24$ to 0.11$)$ & $0.08(-0.09$ to 0.25$)$ & $0.17(-0.01$ to 0.34$)$ & $0.33(0.15-0.47)$ & $0.07(-0.11$ to 0.24$)$ \\
\hline hsCRP $_{\text {Overall Sample }(}(\mathrm{n}=120)^{*}$ & $-0.11(-0.64$ to 0.29$)$ & $0.03(-0.14$ to 0.21$)$ & $0.10(-0.07$ to 0.28$)$ & $0.19(0.01-0.35)$ & $-0.01(-0.18$ to 0.17$)$ \\
\hline hsCRP $_{\text {Sport Practice-No }(n=60)}$ & $0.15(-0.10$ to 0.39$)$ & $-0.06(-0.31$ to 0.19$)$ & $0.36(0.12-0.56)$ & $0.14(-0.11$ to 0.38$)$ & $0.37(0.12-0.56)$ \\
\hline hsCRP $_{\text {Sport Practice-No }(n=60)}{ }^{*}$ & $0.18(-0.08$ to 0.41$)$ & $0.02(-0.23$ to 0.27$)$ & $0.30(0.05-0.51)$ & $0.04(-0.21$ to 0.29$)$ & $0.33(0.07-0.53)$ \\
\hline hsCRP $_{\text {Sport Practice-Yes }(n=60)}$ & $-0.17(-0.41$ to 0.08$)$ & $0.24(-0.01$ to 0.471$)$ & $-0.01(-0.26$ to 0.24$)$ & $0.41(0.17-0.60)$ & $-0.14(-0.38$ to 0.11$)$ \\
\hline hsCRP $_{\text {Sport Practice-Yes }(n=60)^{*}}$ & $-0.24(-0.47$ to 0.01$)$ & $0.10(-0.15$ to 0.34$)$ & $-0.01(-0.26$ to 0.23$)$ & $0.29(0.04-0.51)$ & $-0.19(-0.42$ to 0.06$)$ \\
\hline hsCRP $_{\text {Boys }(n=62)}$ & $-0.04(-0.28$ to 0.21$)$ & $0.20(-0.04$ to 0.43$)$ & $0.03(-0.21$ to 0.28$)$ & $0.41(0.18-0.60)$ & $-0.01(-0.26$ to 0.23$)$ \\
\hline hsCRP $_{\text {Boys }(n=62)}^{\dagger}$ & $-0.14(-0.38$ to 0.10$)$ & $0.11(-0.14$ to 0.34$)$ & $-0.10(-0.15$ to 0.34$)$ & $0.14(-0.10$ to 0.38$)$ & $-0.16(-0.40$ to 0.08$)$ \\
\hline hsCRP $_{\text {Girls }(n=58)}$ & $-0.11(-0.36$ to 0.14$)$ & $-0.02(-0.28$ to 0.23$)$ & $0.25(0.01-0.48)$ & $0.24(-0.01$ to 0.47$)$ & $0.14(-0.11$ to 0.38$)$ \\
\hline hsCRP $_{\text {Girls }(n=58)}{ }^{\dagger}$ & $-0.09(-0.34$ to 16$)$ & $-0.09(-0.34$ to 0.17$)$ & $0.20(-0.05$ to 0.44$)$ & $0.19(-0.07$ to 0.42$)$ & $0.11(-0.15$ to 0.36$)$ \\
\hline
\end{tabular}

*Controlled by age, sex, TF, and somatic maturation.

†Controlled by age, TF, and somatic maturation.

engaged in organized sports participation, the number of steps/day was marginally related to HDL-c $(r=0.24$ [-0.01 to 0.46$])$.

Adolescents with grater hsCRP had increased values of body mass $(P=.001)$, body mass index $(P=.001)$, trunk fatness $(P=.001)$, dyslipidemia score $(P=.001)$, and blood flow $(P=.009)$. In contrast, lower values of HDL-c also were observed in the same group (Table I). In the overall sample, hsCRP was significantly related to HDL-c and dyslipidemia; however, after we controlled for confounder the relationship with HDL-c still significant only in the sedentary group (Table II). Boys and girls had similar relationships.

In the entire sample, only max Bflow femoral $_{\text {was related to }}$ hsCRP. In the sedentary group, fIMT and cIMT + fIMT $_{Z \text {-score }}$ were related to hsCRP (adjusted model). Max Bflow femoral $_{\text {was }}$ still related to the hsCRP in the group that was engaged in 3] sports participation (Table III). In all adjusted models, boys and girls had nonsignificant relationships.

Slopes of the crude linear regression were greater in the group that was not engaged in sports participation for fIMT and cIMT + fIMT $_{Z \text {-score }}$ compared with the group that was engaged in sports participation, but similar to HDL-c (Table IV). There was no difference between boys and girls. The adjusted linear regression model revealed that inflammation was still significantly related to HDL-c $(\beta=-5.797[-11.500$ to -0.093$])$, fIMT $(\beta=0.062$ $[0.008-0.116])$ and cIMT $+\operatorname{fIMT}_{\text {Z-score }}(\beta=1.107[0.223$ -
1.919]) in the group which was not engaged in sports participation.

\section{Discussion}

In these adolescents, inflammatory markers and trunk fatness were significantly related. This finding is particularly interesting because this relationship occurred before the growth spurt. ${ }^{16}$ This finding is potentially concerning because the natural increase of adipose tissue observed throughout maturational events ${ }^{16}$ might exacerbate the harmful relationship between body fatness and inflammation already present during adolescence. ${ }^{17,18}$ Inflammation is commonly related to increased body fatness. ${ }^{1,3}$ Once in the bloodstream, hsCRP alters the genetic expression of the endothelial nitric oxide synthase and increases both the permeability of the vascular wall to low-density lipoprotein cholesterol and the activity of the plasminogen-activator inhibitor- $1 .{ }^{3,19}$ These relationships may explain the association between inflammation and cardiovascular risk markers observed in the sedentary group. ${ }^{7,19}$

The relationship between inflammation and HDL-c was similar to previous research. ${ }^{7,19}$ This lipoprotein is found to be inversely related to inflammatory markers. ${ }^{19}$ However, the absence of a relationship between these variables in the sports participation group was not predicted. In the entire sample, sports practice was not related to either hsCRP or HDL-c. Therefore, the effect of physical exercise on other

Table IV. Slopes of the linear regression (crude) according to engagement in sport participation

\begin{tabular}{|c|c|c|c|c|c|c|}
\hline \multirow[b]{2}{*}{ Variables (X-axis and Y-axis) } & \multirow{2}{*}{$\begin{array}{l}\text { Without sport practice }_{(\mathrm{n}=60)} \\
\beta_{\text {crude }} \pm \mathrm{SE}\end{array}$} & \multirow{2}{*}{$\begin{array}{c}\text { With sport practice } \\
\beta_{\text {crude }} \pm \mathrm{SE}\end{array}$} & \multirow[b]{2}{*}{$\mathbf{t}$} & \multirow[b]{2}{*}{$P$ value } & \multicolumn{2}{|c|}{$\begin{array}{c}\text { Boys }_{(\mathrm{n}=62)} \text { vs girls } \\
58) \\
\end{array}$} \\
\hline & & & & & $t$ & $P$ value \\
\hline hsCRP and HDL-C & $\begin{array}{c}-6.610 \pm 2.382 \mathrm{mg} / \mathrm{dL} \\
\text { Slope }_{P \text {-value }}=.007\end{array}$ & $\begin{array}{c}-6.380 \pm 2.598 \mathrm{mg} / \mathrm{dL} \\
\text { Slope }_{P \text {-value }}=.017\end{array}$ & -0.065 & .948 & -0.0297 & .976 \\
\hline hsCRP and fIMT & $\begin{array}{l}0.066 \pm 0.022 \mathrm{~mm} \\
\text { Slope }_{P \text {-value }}=.004\end{array}$ & $\begin{array}{l}-0.001 \pm 0.013 \mathrm{~mm} \\
\text { Slope }_{P \text {-value }}=.948\end{array}$ & 2.621 & .009 & -1.445 & .150 \\
\hline hsCRP and cIMT + fIMT & $\begin{array}{l}1.062 \pm 0.355 \mathrm{z} \text {-score } \\
\text { Slope }_{P \text {-value }}=.004\end{array}$ & $\begin{array}{c}-0.378 \pm 0.353 \mathrm{z} \text {-score } \\
\text { Slope }_{P \text {-value }}=.289\end{array}$ & 2.876 & .004 & -0.816 & .416 \\
\hline
\end{tabular}


variables related to inflammation and lipid profile should be considered to explain these findings.

Eating behaviors have been suggested as important confounders in the relationship between inflammation and the lipid profile. ${ }^{20,21}$ Consumption of some foods seems to control oxidative stress through DNA methylation, ${ }^{22}$ and some dietary patterns affect proinflammatory markers in pediatric populations. ${ }^{21}$ Therefore, the absence of an association in the active group could be mediated partially by the association between sport practice and better eating behaviors in adolescents. ${ }^{21,23}$

In the present study, the relationship between inflammation and HDL-c could also explain the findings related to vascular structure in the active group. Physical activity of the group engaged in sports was marginally related to HDL-c, which modulates the phosphorylation of the endothelial nitric oxide synthase and would protect the artery wall through lower blood pressure. ${ }^{24}$ However, this pathway does not totally explain our findings, because hsCRP and cIMT + fIMT $_{Z \text {-Score were still related after additional adjust- }}$ ments for blood pressure $(r=0.29[0.04-0.50])$. Thus, it is necessary to consider the anti-inflammatory effect of sport practice in adolescents. ${ }^{25}$

Another potential explanation would be the protective effect of exercise on vascular structure. Physical activity has been related to decreased progression of arterial IMT during adolescence, independent of inflammation. ${ }^{8}$ Recent data have shown that $x_{x x}$ results in greater nitric oxide release, because of wall shear stress and stimulates arteriogenesis and endothelial repair. ${ }^{26}$ This protective effect of exercise on vascular structure may be boosted by maturational events, because it seems to be maintained into later life independent of patterns of physical activity in adulthood. ${ }^{18}$ Finally, the relationship observed only in the femoral artery could be attributed to the fact that this artery has increased oscillation in wall shear rates than other arteries, ${ }^{27}$ which increases the propensity to atherosclerotic events in this artery bed. ${ }^{27,28}$

The relationship between blood flow and markers of inflammation in the active group was not expected. However, several studies have shown that exercise does not always results in favorable improvements in plasma levels of hsCRP. ${ }^{29}$ The alterations in inflammatory markers also may depend on genotype. The relationship between blood flow and markers of inflammation could not be explained by changes in plasma levels of these particular markers. Future studies are needed to better understand this relationship.

Limitations should be recognized. The cross-sectional design of the baseline measures should be taken into account. Second, insulin resistance was not measured. Insulin resistance is a mediator during the vascular inflammatory response and could be helpful to understand the pathways underlying our findings. Even with sample size estimation for the overall sample, the small size sample when stratified according to sport practice should be emphasized. Sex differences were observed in the non-adjusted models, suggesting the existence of a sex-dependent effect on these relationships. Future studies should be planned separately for both boys and girls. Finally, more detail about the sports practice (eg, sport modality, intensity characteristics, and previous time of engagement) would be useful in futures studies. From a health education perspective, our findings emphasize the importance of early physical activity promotion, targeting healthy growth and prevention of diseases in adulthood.

Submitted for publication Jul 29, 2014; last revision received Nov 12, 2014; accepted Dec 18, 2014.

Reprint requests: Suziane Ungari Cayres, MSc, Department of Physical Education, Roberto Simonsen Street, 305, Presidente Prudente, São_Paulo, Brazil. E-mail: suziungari@yahoo.com.br

\section{References}

1. Van Gaal LF, Mertens IL, De Block CE. Mechanisms linking obesity with cardiovascular disease. Nature 2006;444:875-80.

2. Juonala M, Viikari JSA, Rönnemaa T, Taittonen L, Marniemi J, Raitakari OT. Childhood C-reactive protein in predicting CRP and carotid intima-media thickness in adulthood: the Cardiovascular Risk in Young Finns Study. Arterioscler Thromb Vasc Biol 2006; 26:1883-8.

3. Huang PL. eNOS. Metabolic syndrome and cardiovascular disease. Trends Endocrinol Metab 2009;20:295-302.

4. Ignarro LJ, Balestrieri ML, Napoli C. Nutrition, physical activity, and cardiovascular disease: an update. Cardiovasc Res 2007;73:326-40.

5. Leaf DA. The effect of physical exercise on reverse cholesterol transport. Metabolism 2003;52:950-7.

6. Palatini P, Puato M, Rattazzi M, Pauletto P. Effect of regular physical activity on carotid intima-media thickness. Results from a 6-year prospective study in the early stage of hypertension. Blood Press 2011;20:37-44.

7. Silva LR, Cavaglieri C, Lopes WA, Pizzi J, Coelho-e-Silva MJC, Leite N. Endothelial wall thickness, cardiorespiratory fitness and inflammatory markers in obese and non-obese adolescents. Braz J Phys Ther 2014; 18:47-55.

8. Pahkala K, Heinonen OJ, Simell O, Viikari JSA, Rönnemaa T, Niinikoski $\mathrm{H}$, et al. Association of physical activity with vascular endothelial function and intima-media thickness. Circulation 2011;124: 1956-63.

9. Katano H, Ohno M, Yamada K. Protection by physical activity against deleterious effect of smoking on carotid intima-media thickness in young Japanese. J Stroke Cerebrovasc Dis 2013;22:176-83.

10. Li S, Yun M, Fernandez C, Xu J, Srinivasan SR, Chen W, et al. Cigarette smoking exacerbates the adverse effects of age and metabolic syndrome on subclinical atherosclerosis: the Bogalusa Heart Study. PLoS One 2014; 9:e96368.

11. Miot HA. Sample size in clinical and experimental trials. J Vasc Bras 2011;10:275-8

12. Brazilian Society of Cardiology. Standardization of equipment and techniques for conducting examinations vascular ultrasonography. Arq Bras Cardiol 2004;82:1-15.

13. Jourdan C, Wühl E, Litwin M, Fahr K, Trelewicz J, Jobs K, et al. Normative values for intima-media thickness and distensibility of large arteries in healthy adolescents. J Hypertens 2005;23:1707-15.

14. Tudor-Locke C, Craig CL, Beets MW, Belton S, Cardon GM, Duncan S, et al. How many steps/day are enough? For children and adolescents. Int J Behav Nutr Phys Act 2011;8:78.

15. Mirwald RL, Baxter-Jones AD, Bailey DA, Beunen GP. An assessment of maturity from anthropometric measurements. Med Sci Sports Exerc 2002;34:689-94.

16. Knittle JL, Timmers K, Ginsberg-Fellner F, Brown RE, Katz DP. The growth of adipose tissue in children and adolescents. Cross-sectional and longitudinal studies of adipose cell number and size. J Clin Invest 1979;63:239-46.

17. Silveira LS, Monteiro PA, Antunes Bde M, Seraphim PM, Fernandes RA, Christofaro DG, et al. Intra-abdominal fat is related to metabolic 
syndrome and non-alcoholic fat liver disease in obese youth. BMC Pediatr 2013;13:115.

18. Juonala M, Viikari JS, Kähönen M, Taittonen L, Laitinen T, Hutri-Kähönen $\mathrm{N}$, et al. Life-time risk factors and progression of carotid atherosclerosis in young adults: the Cardiovascular Risk in Young Finns study. Eur Heart J 2010;31:1745-51.

19. Rubin DA, McMurray RG, Hackney AC, Harrell JS. Relationship between cardiovascular risk factors and adipokines in adolescents. Horm Res Paediatr 2011;76:123-9.

20. Aatola H, Koivistoinen T, Hutri-Kähönen N, Juonala M, Mikkilä V, Lehtimäki T, et al. Lifetime fruit and vegetable consumption and arterial pulse wave velocity in adulthood: the Cardiovascular Risk in Young Finns Study. Circulation 2010;122:2521-8.

21. Del Mar Bibiloni M, Maffeis C, Llompart I, Pons A, Tur JA. Dietary factors associated with subclinical inflammation among girls. Eur J Clin Nutr 2013;67:1264-70.

22. Mathers JC, Strathdee G, Relton CL. Induction of epigenetic alterations by dietary and other environmental factors. Adv Genet 2010;71:3-39.

23. Fernandes RA, Christofaro DG, Casonatto J, Kawaguti SS, Ronque ER, Cardoso JR, et al. Cross-sectional association between healthy and unhealthy food habits and leisure physical activity in adolescents. J Pediatr 2011;87:252-6.

24. Kelly AS, Hebbel RP, Solovey AN, Schwarzenberg SJ, Metzig AM, Moran A, et al. Circulating activated endothelial cells in pediatric obesity. J Pediatr 2010;157:547-51.

25. Nemet D, Portal S, Zadik Z, Pilz-Burstein R, Adler-Portal D, Meckel Y, et al. Training increases anabolic response and reduces inflammatory response to a single practice in elite male adolescent volleyball players. J Pediatr Endocrinol Metab 2012;25:875-80.

26. Figueiredo PA, Appell Coriolano HJ, Duarte JA. Cardiac regeneration and cellular therapy: is there a benefit of exercise? Int J Sports Med 2014;35:181-90.

27. Rothwell PM. The Interrelation between carotid, femoral and coronary artery disease. Eur Heart J 2001;22:11-4.

28. Wu SP, Ringgaard S, Oyre S, Hansen MS, Rasmus S, Pedersen EM. Wall shear rates differ between the normal carotid, femoral, and brachial arteries: an in vivo MRI study. J Magn Reson Imaging 2004;19:188-93.

29. Marcell TJ, McAuley KA, Traustadóttir T, Reaven PD. Exercise training is not associated with improved levels of C-reactive protein or adiponectin. Metabolism 2005;54:533-41. 